\title{
The Boxdot Conjecture \\ and the Language of Essence and Accident
}

\author{
Christopher Steinsvold \\ Philosophy Department, \\ Brooklyn College, \\ City University of New York \\ steinsvold1@verizon.net
}

Received by Greg Restall

Published February 15, 20II

http://www.philosophy.unimelb.edu.au/ajl/2011

(C) 20II Christopher Steinsvold

Abstract: We show the Boxdot Conjecture holds for a limited but familiar range of Lemmon-Scott axioms. We re-introduce the language of essence and accident, first introduced by J. Marcos, and show how it aids our strategy.

I THE CONJECTURE \& THE LANGUAGE OF ESSENCE AND ACCIDENT

In modal logic, the boxdot translation, $t$, is the following translation:

$$
\begin{aligned}
& \mathrm{t} p=\mathrm{p} \\
& \mathrm{t} \perp=\perp \\
& \mathrm{t}(\phi \rightarrow \psi)=(\mathrm{t} \phi \rightarrow \mathrm{t} \psi) \\
& \mathrm{t} \square \phi=(\square \mathrm{t} \phi \wedge \mathrm{t} \phi)
\end{aligned}
$$

Note that $\mathrm{t} \diamond \phi=(\diamond \mathrm{t} \phi \vee \mathrm{t} \phi)$ and $\mathrm{t} \neg \phi=\neg \mathrm{t} \phi$.

The name derives from $\square \phi$ as an abbreviation for $\square \phi \wedge \phi$ in Boolos [I]. Where $\mathrm{K}$ is the minimal normal modal logic, let $\mathrm{K} \oplus \phi$ be the smallest normal modal logic containing $\phi$. Let $\mathrm{L}$ be some normal modal logic and let $\mathrm{KT}$ be $\mathrm{K} \oplus \square \phi \rightarrow$ $\phi$. French and Humberstone [4] conjectured,

$$
\text { if }(\forall \psi)(K T \vdash \psi \text { if and only if } L \vdash t \psi) \text {, then } L \subseteq K T \text {. }
$$

This is the Boxdot Conjecture. The conjecture was established for normal modal logics of the form $\mathrm{K} \oplus \phi$ with $\phi$ of modal degree I. Here we show the conjecture holds for extensions of $K$ which include any instance of the following axiom schema,

$$
\diamond^{h} \square^{i} p \rightarrow \square^{j} \diamond^{k} p
$$

An instance is given by a specific choice of $h, i, j, k \in\{0,1,2, \ldots\}$. We use $\phi^{\text {hijk }}$ to represent an arbitrary instance. This schema is a limited form of the more 
general Lemmon-Scott axiom schema, see Goldblatt [5]. Clearly, there are infinitely many $\phi^{\text {hijk }}$ which are theorems of KT, thus we show:

$$
\text { for all } \phi^{h i j k} \notin K T,(\exists \psi)\left(K \oplus \phi^{h i j k} \vdash t \psi \text { and } K T \forall \forall \psi\right)
$$

This is our main result. We now begin to discuss our strategy using examples and build up to a discussion of the language of essence and accident which will aid our strategy. For the remainder of this article, assume $q$ and $p$ are distinct.

Consider $\mathrm{K} \oplus \mathrm{D}_{\mathrm{c}}$ (i.e., $\mathrm{K} \oplus \Delta \mathrm{p} \rightarrow \square \mathrm{p}$ ), and the following,

$$
(\neg p \wedge \diamond p) \rightarrow[(q \rightarrow p) \rightarrow \square(q \rightarrow p)]
$$

Call this sentence $S\left(D_{c}\right) . K \vdash(\neg p \wedge \diamond p) \rightarrow \diamond p$, and it straightforward to show that $\mathrm{K} \vdash \square \mathrm{p} \rightarrow[(\mathrm{q} \rightarrow \mathrm{p}) \rightarrow \square(\mathrm{q} \rightarrow \mathrm{p})]$. Thus, $\mathrm{K} \oplus \mathrm{D}_{\mathrm{c}} \vdash \mathrm{S}\left(\mathrm{D}_{\mathrm{c}}\right)$, but $K T \forall S\left(D_{c}\right)$, and we leave it to the reader to find a reflexive frame where $S\left(D_{c}\right)$ fails. Significantly, $S\left(D_{c}\right)$ is K-equivalent to its own translation, i.e.

$$
\mathrm{K} \vdash \mathrm{tS}\left(\mathrm{D}_{\mathrm{c}}\right) \leftrightarrow \mathrm{S}\left(\mathrm{D}_{\mathrm{c}}\right)
$$

Though French and Humberstone already showed this using a different sentence, our example shows that the conjecture holds for $\mathrm{K} \oplus \mathrm{D}_{\mathrm{c}}$. For $\diamond \mathrm{p} \rightarrow \square \mathrm{p} \notin$ $\mathrm{KT}$, and $\mathrm{K} \oplus \mathrm{D}_{\mathrm{c}} \vdash \mathrm{tS}\left(\mathrm{D}_{\mathrm{c}}\right)$ and $\mathrm{KT} \not \mathrm{S}\left(\mathrm{D}_{\mathrm{c}}\right)$. Consider $\mathrm{K} 5$ (i.e. $\mathrm{K} \oplus \diamond \mathrm{p} \rightarrow \square \diamond \mathrm{p}$ ), and the following,

$$
(\neg p \wedge \diamond p) \rightarrow[(\diamond(q \rightarrow p) \vee(q \rightarrow p)) \rightarrow \square(\diamond(q \rightarrow p) \vee(q \rightarrow p))]
$$

Call this sentence $S(5)$. As with the previous example $K 5 \vdash S(5)$, but $S(5)$ is not a theorem of $\mathrm{KT}$ (again, we leave it to the reader to find a reflexive frame where $S(5)$ fails). One can show,

$$
\mathrm{K} \vdash \mathrm{tS}(5) \leftrightarrow \mathrm{S}(5)
$$

Thus the conjecture holds for $\mathrm{K} 5$. $\mathrm{K} 5 \vdash \mathrm{tS}(5), 5 \notin \mathrm{KT}$ and $\mathrm{KT} \forall \mathrm{S}(5)$.

As a final example consider $\mathrm{K} \oplus \mathrm{G} 1$ (i.e. $\diamond \square \mathrm{p} \rightarrow \square \diamond \mathrm{p}$ ) and,

$[(\diamond \neg p \vee \neg p) \wedge \diamond(\square p \wedge p)] \rightarrow[(\diamond(q \rightarrow p) \vee(q \rightarrow p)) \rightarrow \square(\diamond(q \rightarrow p) \vee(q \rightarrow p))]$

Call this $S(G 1)$. Again, $K \oplus G 1 \vdash S(G 1)$ and $K T \not \forall S(G 1)$. Furthermore,

$$
\mathrm{K} \vdash \mathrm{tS}(\mathrm{G} 1) \leftrightarrow \mathrm{S}(\mathrm{G} 1)
$$

Since $\mathrm{G} 1 \notin \mathrm{KT}, \mathrm{K} \oplus \mathrm{G} 1$ is not a counterexample to the conjecture. In each of the three examples, we used a formula K-equivalent to its own translation. We need,

LEMMA I.I For every $\phi$,

$$
\mathrm{K} \vdash \mathrm{tt} \phi \leftrightarrow \mathrm{t} \phi
$$

Proof: This Lemma is Lemma 3.2 of Goris [6]. We omit the proof (which is a straightforward induction on the complexity of formulas). 
We now discuss the language of essence and accident and its relevance to our strategy. The initial study is in Marcos [ [IO], and we re-introduce the basic ideas here. Given the normal modal language, we can define the operators $\circ$ and $\bullet$ with,

$$
\begin{aligned}
& \bullet \phi \stackrel{\text { def }}{=}(\phi \wedge \diamond \neg \phi) \\
& \circ \phi \stackrel{\text { def }}{=}(\phi \rightarrow \square \phi)
\end{aligned}
$$

These operators are the negations of each other (not duals). Thus:

$$
\begin{aligned}
& \mathrm{K} \vdash \bullet \phi \leftrightarrow \neg \circ \phi \\
& \mathrm{K} \vdash \circ \phi \leftrightarrow \neg \bullet \phi
\end{aligned}
$$

Significantly for our purposes, we have:

$$
\begin{gathered}
\mathrm{K} \vdash(\circ \phi \wedge \phi) \leftrightarrow(\square \phi \wedge \phi) \\
\mathrm{K} \vdash(\bullet \neg \phi \vee \phi) \leftrightarrow(\diamond \phi \vee \phi)
\end{gathered}
$$

Read $\bullet \phi$ as: $\phi$ is accidentally true. Read $\circ \phi$ as: $\phi$ is essentially true. Synonymously, we may read $\bullet \phi$ as symbolizing the contingent truth of $\phi$ (true in this world though false in another). The study of the language of essence and accident may be seen as a variation on the study of contingency logics (where an operator symbolizing $\diamond \phi \wedge \diamond \neg \phi$ is studied (see Brogan [2]-presenting Aristotle's views - and Cresswell [3], Humberstone [7], Kuhn [8], Lomuscio and Van der Hoek [9], Montgomery and Routley [II], Mortensen [I2], Steinsvold [I3], Zolin [15]).

DEFINITION I.2 The set of formulas of essence and accident, $\mathfrak{F}^{\text {EA }}$, is that subset of the formulas of normal modal logic which can be formed using only propositional variables, the Boolean connectives, parentheses, $\bullet$, and $\circ$.

We now prove a useful fact about the members of $\mathfrak{F}^{\mathrm{EA}}$.

LEMMA I.3 for all $\phi \in \mathfrak{F}^{\mathrm{EA}}$,

$$
\mathrm{K} \vdash \mathrm{t} \phi \leftrightarrow \phi
$$

Proof: We show by induction on the complexity of formulas. Clearly, $t p=p$ and $\mathrm{t} \perp=\perp$. By definition, $\mathrm{t}(\phi \rightarrow \psi)=(\mathrm{t} \phi \rightarrow \mathrm{t} \psi)$, thus $\mathrm{K} \vdash(\mathrm{t} \phi \rightarrow \mathrm{t} \psi) \leftrightarrow$ $\mathrm{t}(\phi \rightarrow \psi)$. By the induction hypothesis we know that $\mathrm{K} \vdash \phi \leftrightarrow \mathrm{t} \phi$ and $\mathrm{K} \vdash$ $\psi \leftrightarrow \mathrm{t} \psi$. Thus, by replacement we know $\mathrm{K} \vdash(\phi \rightarrow \psi) \leftrightarrow \mathrm{t}(\phi \rightarrow \psi)$.

To show $\mathrm{K} \vdash \mathrm{t} \bullet \phi \leftrightarrow \bullet \phi$,

I) $K \vdash(\phi \wedge(\diamond \neg \phi \vee \neg \phi)) \leftrightarrow(\phi \wedge \diamond \neg \phi)$, theorem of $K$.

2) $K \vdash \phi \leftrightarrow t \phi$, by the induction hypothesis.

3) $\mathrm{K} \vdash \neg \phi \leftrightarrow \mathrm{t} \neg \phi$, from 2 negate both sides and use $\mathrm{t} \neg \phi=\neg \mathrm{t} \phi$.

4) $\mathrm{K} \vdash(\mathrm{t} \phi \wedge(\diamond \mathrm{t} \neg \phi \vee \mathrm{t} \neg \phi)) \leftrightarrow(\phi \wedge \diamond \neg \phi)$ Using 2 and 3 with line $\mathrm{I}$.

5) $\mathrm{K} \vdash(\mathrm{t} \phi \wedge \mathrm{t} \diamond \neg \phi) \leftrightarrow(\phi \wedge \diamond \neg \phi)$, from 4 , using $\mathrm{t} \diamond \neg \phi=(\diamond \mathrm{t} \neg \phi \vee \mathrm{t} \neg \phi))$.

6) $\mathrm{K} \vdash \mathrm{t} \bullet \phi \leftrightarrow \bullet \phi$, via 5 with $(\mathrm{t} \phi \wedge \mathrm{t} \diamond \neg \phi)=\mathrm{t}(\phi \wedge \diamond \neg \phi), \bullet \phi=(\phi \wedge \diamond \neg \phi)$. 
Lemma I.3 explains why $S\left(D_{c}\right)$ is equivalent, in $K$, to its own translation. Note that we may rewrite $S\left(D_{c}\right)$ as $\bullet \neg p \rightarrow \circ(q \rightarrow p)$.

Let $\phi^{\mathrm{EA}}$ be an arbitrary formula from $\mathfrak{F}^{\mathrm{EA}}$ and let $\phi^{\square}$ be an arbitrary boxdot formula (a formula of normal modal logic is a boxdot formula if there is a formula of normal modal logic which it is the translation of). From Lemma I.3 we have,

THEOREM I. 4 For every $\phi^{\mathrm{EA}}$ there is some $\psi^{\square}$ such that,

$$
\mathrm{K} \vdash \phi^{\mathrm{EA}} \leftrightarrow \psi^{\square}
$$

Proof: $t \phi^{\mathrm{EA}}$ is a boxdot formula and from Lemma $\mathrm{I} \cdot 3, \mathrm{~K} \vdash \phi^{\mathrm{EA}} \leftrightarrow \mathrm{t} \phi^{\mathrm{EA}}$

THEOREM I. 5 For all $\phi^{\square}$, there is some $\psi^{\mathrm{EA}}$ such that,

$$
\mathrm{K} \vdash \phi^{\square} \leftrightarrow \psi^{\mathrm{EA}}
$$

Proof: This follows from the fact that $K \vdash(\square \phi \wedge \phi) \leftrightarrow(\circ \phi \wedge \phi)$. Given $\phi^{\square}$, mark every $\square$ and then replace every marked $\square$ with $\circ$.

Thus for every $\psi^{\square}$ there is an equivalent $\phi^{\mathrm{EA}}$ and for every $\phi^{\mathrm{EA}}$ there is an equivalent $\psi^{\square}$; which will we use? Both. $S(5)$ can be re-written,

$$
\bullet \neg p \rightarrow \text { ot } \diamond(q \rightarrow p)
$$

Similarly, S(G1) can be re-written,

We need,

$$
\bullet t \diamond \neg p \rightarrow \circ t \diamond(q \rightarrow p)
$$

THEOREM I.6 If $L \subseteq K T$, then the following rule of inference holds,

$$
\text { If } \mathrm{L} \vdash \phi \rightarrow \psi \text { then } \mathrm{L} \vdash \mathrm{t} \phi \rightarrow \mathrm{t} \psi
$$

Proof: As French and Humberstone [4] note, we have for all $\mathrm{L} \subseteq \mathrm{KT}$,

$$
(\forall \phi)(\mathrm{L} \vdash \mathrm{t} \phi \text { iff } \mathrm{KT} \vdash \phi)
$$

Now assume $L \vdash \phi \rightarrow \psi$ but $L \forall t \phi \rightarrow t \psi$. Since $L \subseteq K T, K T \vdash \phi \rightarrow \psi$. Since $\mathrm{L} \forall \forall \rightarrow \rightarrow \mathrm{t} \psi, \mathrm{L} \forall \forall(\phi \rightarrow \psi)$ (by the definition of $\mathrm{t}$ ). But by the faithful embedding just mentioned, $\mathrm{KT} \forall \phi \rightarrow \psi$, contradiction.

The following rules of inference will be helpful, COROLLARY I.7 I) If $\mathrm{K} \vdash \phi \rightarrow \psi$ then $\mathrm{K} \vdash \mathrm{t} \phi \rightarrow \mathrm{t} \psi$.

2) If $K \vdash \phi \leftrightarrow \psi$ then $K \vdash t \phi \leftrightarrow t \psi$

Proof: From Theorem I.6

We now outline our overall strategy. Given some $\phi^{\text {hijk }} \notin K T$, we will construct a surrogate sentence, $S\left(\phi^{\text {hijk }}\right)$, and show $\mathrm{K} \oplus \phi^{\text {hijk }} \vdash \mathrm{S}\left(\phi^{\text {hijk }}\right)$. Each $S\left(\phi^{\text {hijk }}\right)$ will be constructed entirely out of $\phi^{\square}$ and $\phi^{\mathrm{EA}}$ formulas, so that $K \vdash \mathrm{tS}\left(\phi^{\text {hijk }}\right) \leftrightarrow \mathrm{S}\left(\phi^{\mathrm{hijk}}\right)$. Thus $\mathrm{K} \oplus \phi^{\mathrm{hijk}} \vdash \mathrm{tS}\left(\phi^{\mathrm{hijk}}\right)$. The final step in our 
strategy is to show that $S\left(\phi^{\text {hijk }}\right)$ fails in a reflexive model, and hence is not a theorem of KT.

In fact, for the last step, it will be sufficient to show that $S\left(\phi^{\text {hijk }}\right)$ fails in some model. As observed in Marcos [IO], if $\phi^{\mathrm{EA}}$ fails in any model, then it fails in a reflexive model. We repeat this proof below (Lemma 2.2). We end this introduction by stressing a basic fact about the language of essence and accident: the language is insensitive to reflexivity.

Given a normal modal logic $\mathrm{L}$, let $\mathrm{L}^{\mathrm{EA}}=\left\{\phi^{\mathrm{EA}} \mid \mathrm{L} \vdash \phi^{\mathrm{EA}}\right\}$. Using an insight from Kuhn [8], Marcos [IO] introduced and gave a completeness proof for $\mathrm{K}^{\mathrm{E} A}$ (the minimal logic of essence and accident). In a follow-up article to Marcos [IOl, Steinsvold [I4] showed completeness results for various LEA logics. It was shown that for any normal modal logic $\mathrm{L}$ such that $\mathrm{K} \subseteq \mathrm{L} \subseteq \mathrm{KT}, \mathrm{K}^{\mathrm{EA}}=\mathrm{L}^{\mathrm{EA}}=$ $K T^{E A}$. Also, since $K^{E A}=K T^{E A}$, to show that a logic $L$ is not a counterexample to the Boxdot Conjecture, it is sufficient to show there is some $\phi^{\mathrm{EA}} \in \mathrm{L}-\mathrm{K}$; this is the strategy we employ.

\section{POSSIBLE WORLD SEMANTICS}

A frame $F=\langle W, R\rangle$ is a non-empty set $W$ where $R \subseteq W \times W$. Members of $W$ are worlds or points. A valuation $\mathrm{V}$ is a function from the set of propositional variables into the power set of $W . M=\langle W, R, V\rangle$ is a model. We define truth in a model at a world as follows:

$$
\begin{aligned}
& M, w \models p \text { iff } w \in V(p) \\
& M, w \models \perp \text { iff } 0=1 \\
& M, w \models \phi \rightarrow \psi \text { iff if } M, w \models \phi \text { then } M, w \models \psi \\
& M, w \models \square \phi \text { iff }(\forall x)(\text { if } w R x \text { then } M, x \models \phi) \\
& M, w \models \bullet \phi \text { iff } M, w \models \phi \text { and }(\exists x)(w R x \text { and } M, x \not \models \phi)
\end{aligned}
$$

Definition 2.I Given a model $M=\langle W, R, V\rangle$, the REFLEXIVIzation of $M$ is $M^{r}=\left\langle W, R^{r}, V\right\rangle$, where $R^{r}=R \cup\{(x, x) \mid x \in W\}$

Simply put, the reflexivization of a model replaces $R$ with its reflexive closure. The following is due to Marcos [IO] and will be used later on.

LEMMA 2.2 Let $M=\langle W, R, V\rangle$ be any model and let $\phi \in \mathfrak{F}^{\mathrm{EA}}$.

$$
M, w \models \phi \text { iff } M^{r}, w \models \phi .
$$

Proof: By induction. The non-modal cases are straightforward. Assume $M, w \models$ $\bullet \phi$ then $M, w \models \phi$ and for some $y, w R y$ and $M, y \not \models \phi$. By the induction hypothesis, $M^{r}, w \models \phi$ and $M^{r}, y \not \models \phi$. Since $w R^{r} y, M^{r}, w \models \bullet \phi$. Conversely, if $M^{r}, w \models \bullet \phi$ then $M^{r}, w \models \phi$ and for some $x, w R^{r} x$ and $M^{r}, x \not \models \phi$. Clearly, $w \neq x$, thus by the induction hypothesis, $M, w \models \bullet \phi$

Thus, for any $\phi^{\mathrm{EA}}$ true at any point in any model, $\phi^{\mathrm{EA}}$ will still be true in the reflexivization of that model at that point. We also have, 
LEMMA 2.3 Let $M=\langle W, R, V\rangle$ be any model.

$$
M, w \models \phi^{\square} \text { iff } M^{r}, w \models \phi^{\square} .
$$

Proof: Assume $M, w \models \phi^{\square}$. By Theorem I.5, K $\vdash \phi^{\mathrm{EA}} \leftrightarrow \phi^{\square}$ for some $\phi^{\mathrm{EA}}$. Thus $M, w \models \phi^{\mathrm{EA}}$. By Lemma 2.2, $M^{\mathrm{r}}, w \models \phi^{\mathrm{EA}}$, so $M^{\mathrm{r}}, w \models \phi^{\square}$. The converse is similar.

\section{A NeCESSARY AND SUFFICIENT CONDITION FOR $\phi^{\text {hijk }} \in$ KT}

There are infinitely many $\phi^{\text {hijk }} \in K T$ and we need to isolate them. This includes isolating those $\phi^{\text {hijk }}$ which are also theorems of $\mathrm{K}$ (viz. $\mathrm{p} \rightarrow \mathrm{p}, \square \mathrm{p} \rightarrow$ $\square p$, and so on).

DEFINITION 3.I For any $\phi^{\text {hijk, }}$

$$
\begin{aligned}
& \phi^{h i j k} \text { is a } T^{\square} \text { SENTENCE iff } h=0 \text { and } i \geqslant j \\
& \phi^{h i j k} \text { is a } T^{\diamond} \text { SENTENCE iff } j=0 \text { and } k \geqslant h
\end{aligned}
$$

We prove the following Lemma and then the converse of it.

LEMMA 3.2 If $\phi^{\text {hijk }}$ is a $T^{\square}$ or $T^{\diamond}$ sentence, then $K T \vdash \phi^{\text {hijk }}$.

Proof: We show for the case of $\mathrm{T}^{\square}$ sentences, using induction on $i$.

Base case, $i=0$. Since $i=0$ and $i \geqslant j, j=0$. We know $h=0$, thus we must show KT $\vdash p \rightarrow \diamond^{k} p$, for all $k$. Clearly, KT $\vdash p \rightarrow p$. Since KT $\vdash \phi \rightarrow \diamond \phi$ we have KT $\vdash \diamond^{n} p \rightarrow \diamond^{n+1} p$, for all $n \geqslant 0$. Thus, KT $\vdash p \rightarrow \diamond^{k} p$, for all $k$.

For the inductive step assume KT $\vdash \square^{i} p \rightarrow \square^{j} \diamond^{k} p$. KT $\vdash \square^{i+1} p \rightarrow \square^{i} p$, thus $\mathrm{KT} \vdash \square^{\mathrm{i}+1} p \rightarrow \square^{\mathrm{j}} \diamond^{\mathrm{k}} p$.

The case for $T^{\diamond}$ sentences is a dual variation of this argument.

LEMMA 3.3 If $K T \vdash \phi^{\text {hijk }}$ then $\phi^{\text {hijk }}$ is a $T^{\square}$ or $T^{\diamond}$ sentence.

Proof: Assume $\phi^{\text {hijk }}$ is neither a $\mathrm{T}^{\square}$ nor a $\mathrm{T}^{\diamond}$ sentence. Thus we know:

I) Either $h \neq 0$ or $i<j$, and

2) Either $j \neq 0$ or $k<h$.

We have four cases.

CASE $\mathrm{I}: \mathrm{h} \neq 0$ and $j \neq 0$. Let $h=n+1$ and $j=m+1$, where $n, m \geqslant 0$. Thus $\phi^{\text {hijk }}$ is of the form $\diamond \nabla^{n} \square^{i} p \rightarrow \square \square^{m} \diamond^{k} p$.

Let $M=\langle W, R, V\rangle$ where $W=\{a, b, c\}, R=\{(a, b),(a, c)\}$ and $V(p)=\{b\}$. Now consider the reflexivization of $M, M^{r}$ (see Definition 2.I). Since $b$ only bears $R^{r}$ to itself and $M^{r}, b \models p, M^{r}, b \models \diamond^{n} \square^{i} p$. Since $c$ only bears $R^{r}$ to itself and $M^{r}, c \models \neg p, M^{r}, c \models \diamond^{m} \square^{k} \neg p$. Since $a R^{r} b, M^{r}, a \models \Delta \diamond^{n} \square^{i} p$. Since $a R^{r} c, M^{r}, a \models \Delta \diamond^{m} \square^{k} \neg p$. Since $M^{r}$ is reflexive, $\diamond \diamond^{n} \square^{i} p \rightarrow \square \square^{m} \diamond^{k} p$ is not a theorem of KT.

CASE 2: $h \neq 0$ and $k<h$. To get a contradiction, assume, 
I) $K T \vdash \diamond^{h} \square^{i} p \rightarrow \square^{j} \diamond^{k} p$ (assumption for reductio).

2) $\mathrm{KT} \vdash \square^{j} \diamond^{k} p \rightarrow \diamond^{k} p$, from $K T \vdash \square^{j} \phi \rightarrow \phi$, where $\phi$ is $\diamond^{k} p$.

3) $\mathrm{KT} \vdash \diamond^{h} \square^{i} p \rightarrow \diamond^{k} p$, from $\mathrm{I}$ and 2 , classical logic.

Let $M=\langle\mathbb{N}, R, V\rangle$, where $x R y$ iff $x=y$ or $y$ is the immediate successor of $x$, and $V(p)=\{n \in \mathbb{N} \mid h \leqslant n\}$.

Since $k$ is strictly less than $h, M, 0 \models \neg \nabla^{k} p$. And $M, 0 \models \nabla^{h} \square^{i} p$, regardless of the size of $i$. Since $M$ is reflexive, $\diamond^{h} \square^{i} p \rightarrow \diamond^{k} p$ is not a theorem of KT. Contradiction.

CASE $3: i<j$ and $j \neq 0$. Assume KT proves this $\phi^{\text {hijk }}$. Substitute $\neg p$ for $p$ and take the contraposition of $\phi^{\text {hijk }}$. This case is isomorphic to the second case, and the same argument applies.

CASE $4: i<j$ and $k<h$. $i$ and $k$ can't be lower than zero, thus $h \neq 0$ and $j \neq 0$. But this case is subsumed by the first case.

THEOREM 3.4 For all $\phi^{\text {hijk }}$,

$$
\mathrm{KT} \vdash \phi^{\text {hijk }} \text { iff } \phi^{\text {hijk }} \text { is a } \mathrm{T}^{\square} \text { or } \mathrm{T}^{\diamond} \text { sentence }
$$

Proof: From Lemmas 3.2 and 3.3

\section{CONSTRUCTION OF SURROGATES}

For each $\phi^{\text {hijk }} \notin \mathrm{KT}$, we will construct a surrogate sentence, $\mathrm{S}\left(\phi^{\text {hijk }}\right)$, where $K \oplus \phi^{\text {hijk }} \vdash S\left(\phi^{\text {hijk }}\right)$. Each $S\left(\phi^{\text {hijk }}\right)$ will be constructed entirely out of $\phi^{\text {EA }}$ and $\phi^{\square}$ sentences, so that $\mathrm{K} \vdash \mathrm{tS}\left(\phi^{\text {hijk }}\right) \leftrightarrow \mathrm{S}\left(\phi^{\text {hijk }}\right)$.

To help introduce our surrogates, assume $\phi^{\text {hijk }} \notin \mathrm{KT}$. By Theorem 3.4 we know $\phi^{\text {hijk }}$ is not a $T^{\square}$ sentence, i.e. either $h \neq 0$ or $i<j$.

If $h \neq 0$, we show there is a surrogate for $\phi^{\text {hijk }}$ of the following form $(h=n+1)$,

$$
\bullet \neg \mathrm{t} \diamond^{\mathrm{n}} \square^{\mathrm{i}} \mathrm{p} \rightarrow \mathrm{o}^{\mathrm{j}} \mathrm{t} \diamond^{\mathrm{k}}(\mathrm{q} \rightarrow \mathrm{p})
$$

If $i<j$, we show there exists a surrogate for $\phi^{\text {hijk }}$ of the following form (where $j=n+1)$,

$$
\bullet-t \diamond^{n} \square^{k} p \rightarrow o^{h} t \diamond^{i}(q \rightarrow p)
$$

We encourage the reader to view in advance the proof of Theorem 4.15 to gain a better notion of the direction of this section. We must show a number of preliminary results first.

We only need one surrogate for each $\phi^{\text {hijk }} \notin \mathrm{KT}$. S $\left(\phi^{\text {hijk }}\right)$ will represent an arbitrary surrogate for $\phi^{\text {hijk }}$, and we will give an official definition of surrogate for $\phi^{\text {hijk }}$ below (Definition 4.I6).

The general strategy is as follows. Given $\phi^{\text {hijk }} \notin \mathrm{KT}$, we want $\mathrm{K}$ to prove that the antecedent of $S\left(\phi^{\text {hijk }}\right)$ implies the antecedent of $\phi^{\text {hijk }}$. Furthermore, 
we want $K$ to prove that the consequent of $\phi^{\text {hijk }}$ implies the consequent of $S\left(\phi^{h i j k}\right)$. Granting this, we have $K \oplus \phi^{\text {hijk }} \vdash S\left(\phi^{\text {hijk }}\right)$.

The next results pertain to the the consequents of $\phi^{\text {hijk }}$ and $S\left(\phi^{\text {hijk }}\right)$. LEMma 4.I If $K \vdash \phi \rightarrow \psi$ then $K \vdash \square^{n} \phi \rightarrow \circ^{n} \psi$ for all $n \geqslant 0$.

Proof: By induction. The base case $(\mathrm{n}=0)$ is: if $\mathrm{K} \vdash \phi \rightarrow \psi, \mathrm{K} \vdash \phi \rightarrow \psi$.

I) $K \vdash \square^{n} \phi \rightarrow \circ^{n} \psi$, by the induction hypothesis.

2) $\mathrm{K} \vdash \square \square^{\mathrm{n}} \phi \rightarrow \square \circ^{\mathrm{n}} \psi$, from $\mathrm{I}$, normality.

3) $\mathrm{K} \vdash \square \square^{\mathrm{n}} \phi \rightarrow\left(\circ^{\mathrm{n}} \psi \rightarrow \square \circ^{\mathrm{n}} \psi\right)$, from 2 , weakening the consequent.

4) $\mathrm{K} \vdash \square^{\mathrm{n}+1} \phi \rightarrow \circ^{\mathrm{n}+1} \psi$, from 3 and the definition of $\circ$.

LEMMA $4.2 \mathrm{~K} \vdash \diamond^{\mathrm{n}} \mathrm{p} \rightarrow \mathrm{t} \diamond^{\mathrm{n}}(\mathrm{q} \rightarrow \mathrm{p})$ all $\mathrm{n} \geqslant 0$.

Proof: By induction. The base case $(\mathrm{n}=0)$ is immediate. $\mathrm{K} \vdash \mathrm{p} \rightarrow(\mathrm{q} \rightarrow \mathrm{p})$, and by the definition of $t, t(q \rightarrow p)=(q \rightarrow p)$. For the inductive step,

I) $K \vdash \diamond^{n} p \rightarrow t \diamond^{n}(q \rightarrow p)$, by the induction hypothesis.

2) $\mathrm{K} \vdash \Delta \diamond^{n} p \rightarrow \diamond t \diamond^{n}(q \rightarrow p)$, from I, normality.

3) $K \vdash \Delta \diamond^{n} p \rightarrow\left(\diamond t \diamond^{n}(q \rightarrow p) \vee t \diamond^{n}(q \rightarrow p)\right)$, weakening consequent of 2 .

4) $K \vdash \diamond^{n+1} p \rightarrow t \diamond^{n+1}(q \rightarrow p)$, from 3 and definition of $t$.

LEMMA $4.3 \mathrm{~K} \vdash \square^{\mathrm{m}} \diamond^{\mathrm{n}} \mathrm{p} \rightarrow \mathrm{o}^{\mathrm{m}} \mathrm{t} \diamond^{\mathrm{n}}(\mathrm{q} \rightarrow \mathrm{p})$ all $\mathrm{m}, \mathrm{n} \geqslant 0$

Proof: From Lemmas 4.1 and 4.2 .

Half of our strategy is fulfilled. Lemma 4.3 tells us $\mathrm{K}$ proves that the consequent of $\phi^{\text {hijk }}$ implies the consequent of $S\left(\phi^{\text {hijk }}\right)$.

The next results pertain to the antecedents of $\phi^{\text {hijk }}$ and $S\left(\phi^{\text {hijk }}\right)$. We need to show $K$ proves that the antecedent of $S\left(\phi^{\text {hijk }}\right)$ implies the antecedent of $\phi^{\text {hijk }}$. To do this, we need the antecedent of $S\left(\phi^{\text {hijk }}\right)$ in a more manageable form. Focusing on the case where $h$ is not zero, and letting $h=n+1$, the antecedent of $S\left(\phi^{\text {hijk }}\right)$ is $\bullet \neg t \nabla^{n} \square^{i} p$. By the definition of $\bullet$ we know $\bullet \neg t \nabla^{n} \square^{i} p$ is $\left(\neg t \diamond^{n} \square^{i} p \wedge \Delta t \diamond^{n} \square^{i} p\right)$. In order to show that $K \vdash \bullet \neg t \nabla^{n} \square^{i} p \rightarrow \diamond^{h} \square^{i} p$, we show that,

$$
K \vdash \bullet \neg t \diamond^{n} \square^{i} p \leftrightarrow\left(\neg t \diamond^{n} \square^{i} p \wedge \diamond^{n+1} t \square^{i} p\right)
$$

Most of the work in this section is in showing the above. In the next few results we work to show the sentence on the right hand of the bi-conditional above implies the antecedent of $\phi^{\text {hijk }}$. Once we have all of this, we can conclude that the antecedent of the surrogate implies the antecedent of $\phi^{\text {hijk }}$.

LEMMA $4.4 \mathrm{~K} \vdash \mathrm{t} \square^{\mathrm{n}} \mathrm{p} \rightarrow \square^{\mathrm{n}} \mathrm{p}$ all $\mathrm{n} \geqslant 0$. 
Proof: By induction on $n$. The base case is $n=0$. But $t p=p, K \vdash p \rightarrow p$.

I) $\mathrm{K} \vdash \mathrm{t} \square^{\mathrm{n}} \mathrm{p} \rightarrow \square^{\mathrm{n}} \mathrm{p}$, by the induction hypothesis.

2) $\mathrm{K} \vdash \square \mathrm{t} \square^{\mathrm{n}} \mathrm{p} \rightarrow \square \square^{\mathrm{n}} \mathrm{p}$, from I, normality.

3) $\mathrm{K} \vdash\left(\square t \square^{\mathrm{n}} \mathrm{p} \wedge t \square^{\mathrm{n}} \mathrm{p}\right) \rightarrow \square \square^{\mathrm{n}} \mathrm{p}$, from 2 , strengthening the antecedent.

4) $K \vdash t \square^{n+1} p \rightarrow \square^{n+1} p$, from 3 and the definition of $t$.

LEMMA $4.5 K \vdash\left(\neg t \diamond^{n} \square^{m} p \wedge \diamond^{n+1} t \square^{m} p\right) \rightarrow \diamond^{n+1} \square^{m} p$ for all $m, n \geqslant 0$.

Proof: I) $\mathrm{K} \vdash \mathrm{t} \square^{\mathrm{m}} \mathrm{p} \rightarrow \square^{\mathrm{m}} \mathrm{p}$, by Lemma 4.4

But if $K \vdash \phi \rightarrow \psi$ then $K \vdash \diamond^{n+1} \phi \rightarrow \diamond^{n+1} \psi$, by normality. Thus,

2) $K \vdash \diamond^{n+1} t \square^{m} p \rightarrow \diamond^{n+1} \square^{m} p$. Strengthening the antecedent we get,

3) $K \vdash\left(\neg t \diamond^{n} \square^{m} p \wedge \diamond^{n+1} t \square^{m} p\right) \rightarrow \diamond^{n+1} \square^{m} p$ for all $m, n \geqslant 0$.

We now focus on showing $K \vdash\left(\neg t \diamond^{n} \square^{m} p \wedge \nabla^{n+1} t \square^{m} p\right) \leftrightarrow\left(\bullet \neg t \diamond^{n} \square^{m} p\right)$. LEMMA $4.6 \mathrm{~K} \vdash \diamond^{\mathrm{n}} \mathrm{t} \square^{\mathrm{m}} \mathrm{p} \rightarrow \mathrm{t} \diamond^{\mathrm{n}} \square^{\mathrm{m}} \mathrm{p}$ all $\mathrm{m}, \mathrm{n} \geqslant 0$.

Proof: By induction on $\mathrm{n}$. Where $\mathrm{n}=0$ we have $\mathrm{K} \vdash \mathrm{t} \square^{\mathrm{m}} \mathrm{p} \rightarrow \mathrm{t} \square^{\mathrm{m}} \mathrm{p}$

I) $K \vdash \diamond^{n} t \square^{m} p \rightarrow t \nabla^{n} \square^{m} p$, by the induction hypothesis.

2) $\mathrm{K} \vdash \diamond \diamond^{n} t \square^{\mathrm{m}} \mathrm{p} \rightarrow \diamond \mathrm{t} \diamond^{\mathrm{n}} \square^{\mathrm{m}} \mathrm{p}$, from I, normality.

3) $\mathrm{K} \vdash \Delta \diamond^{n} t \square^{\mathrm{m}} \mathrm{p} \rightarrow\left(\diamond \mathrm{t} \diamond^{n} \square^{\mathrm{m}} \mathrm{p} \vee \mathrm{t} \diamond^{n} \square^{\mathrm{m}} \mathrm{p}\right)$, weakening consequent of 2 .

4) $K \vdash \diamond^{n+1} t \square^{m} p \rightarrow t \nabla^{n+1} \square^{m} p$, from 3 and the definition of $t$.

Lemma 4.7 For all all $m, n \geqslant 0$,

$\mathrm{K} \vdash\left(\neg \mathrm{t} \diamond^{\mathrm{n}} \square^{\mathrm{m}} \mathrm{p} \wedge \nabla^{\mathrm{n}+1} \mathrm{t} \square^{\mathrm{m}} \mathrm{p}\right) \rightarrow\left(\neg \mathrm{t} \diamond^{\mathrm{n}} \square^{\mathrm{m}} \mathrm{p} \wedge \Delta_{\mathrm{t}} \diamond^{\mathrm{n}} \square^{\mathrm{m}} \mathrm{p}\right)$

Proof: From Lemma 4.6 we have,

I) $K \vdash \diamond^{n} t \square^{m} p \rightarrow t \nabla^{n} \square^{m} p$

2) $\mathrm{K} \vdash \diamond \diamond^{n} t \square^{\mathrm{m}} p \rightarrow \diamond t \diamond^{n} \square^{\mathrm{m}} p$, from I, normality.

3) $K \vdash\left(\neg t \diamond^{n} \square^{m} p \wedge \diamond^{n+1} t \square^{m} p\right) \rightarrow\left(\neg t \diamond^{n} \square^{m} p \wedge \diamond t \diamond^{n} \square^{m} p\right)$, from 2 using, if $\mathrm{K} \vdash \phi \rightarrow \psi$ then $\mathrm{K} \vdash(\theta \wedge \phi) \rightarrow(\theta \wedge \psi))$, where $\theta$ is $\neg \mathrm{t} \diamond^{\mathrm{n}} \square^{\mathrm{m}} \mathrm{p}$,

We now work to show $\mathrm{K}$ proves the converse of Lemma $4 \cdot 7$ LEMMA $4.8 K \vdash \mathrm{t} \diamond^{n} \phi \leftrightarrow\left(\diamond^{n} \mathrm{t} \phi \vee \diamond^{n-1} \mathrm{t} \phi \vee \cdots \vee \diamond \mathrm{t} \phi \vee \mathrm{t} \phi\right)$

Proof: By induction on $n$. Where $n=0$ (base case), $K \vdash t \phi \leftrightarrow t \phi$.

I) $K \vdash t \diamond^{n} \phi \leftrightarrow\left(\nabla^{n} t \phi \vee \nabla^{n-1} t \phi \vee \cdots \vee \diamond t \phi \vee t \phi\right)$, by the induction hypothesis.

2) $\mathrm{K} \vdash \mathrm{t} \diamond^{\mathrm{n}} \phi \rightarrow\left(\diamond^{\mathrm{n}} \mathrm{t} \phi \vee \diamond^{\mathrm{n}-1} \mathrm{t} \phi \vee \cdots \vee \diamond \mathrm{t} \phi \vee \mathrm{t} \phi\right)$, from I

3) $\mathrm{K} \vdash \diamond_{\mathrm{t}} \diamond^{\mathrm{n}} \phi \rightarrow \diamond\left(\diamond^{\mathrm{n}} \mathrm{t} \phi \vee \diamond^{\mathrm{n}-1} \mathrm{t} \phi \vee \cdots \vee \diamond \mathrm{t} \phi \vee \mathrm{t} \phi\right)$, from 2, normality.

4) $\mathrm{K} \vdash \Delta \mathrm{t} \diamond^{\mathrm{n}} \phi \rightarrow\left(\diamond^{\mathrm{n}+1} \mathrm{t} \phi \vee \diamond^{\mathrm{n}} \mathrm{t} \phi \vee \cdots \vee \diamond \mathrm{t} \phi\right)$, from 3, distributing the diamonds over disjunction. 
5) $\mathrm{K} \vdash \diamond_{\mathrm{t}} \diamond^{\mathrm{n}} \phi \rightarrow\left(\diamond^{\mathrm{n}+1} \mathrm{t} \phi \vee \diamond^{\mathrm{n}} \mathrm{t} \phi \vee \cdots \vee \diamond \mathrm{t} \phi \vee \mathrm{t} \phi\right)$, weakening line 4.

6) $\mathrm{K} \vdash \mathrm{t} \nabla^{\mathrm{n}} \phi \rightarrow\left(\diamond^{\mathrm{n}+1} \mathrm{t} \phi \vee \diamond^{\mathrm{n}} \mathrm{t} \phi \vee \cdots \vee \diamond \mathrm{t} \phi \vee \mathrm{t} \phi\right)$, weakening line 2.

7) $\mathrm{K} \vdash\left(\mathrm{t} \diamond^{\mathrm{n}} \phi \vee \diamond \mathrm{t} \diamond^{\mathrm{n}} \phi\right) \rightarrow\left(\diamond^{\mathrm{n}+1} \mathrm{t} \phi \vee \diamond^{\mathrm{n}} \mathrm{t} \phi \vee \cdots \vee \diamond \mathrm{t} \phi \vee \mathrm{t} \phi\right)$, from 5, 6

8) $\mathrm{K} \vdash \mathrm{t} \diamond^{\mathrm{n}+1} \phi \rightarrow\left(\diamond^{\mathrm{n}+1} \mathrm{t} \phi \vee \diamond^{n} \mathrm{t} \phi \vee \cdots \vee \diamond \mathrm{t} \phi \vee \mathrm{t} \phi\right)$, from 7 , by def. of $\mathrm{t}$.

9) $K \vdash\left(\diamond^{n} t \phi \vee \diamond^{n-1} t \phi \vee \cdots \vee \diamond t \phi \vee t \phi\right) \rightarrow t \diamond^{n} \phi$, from I.

Iо) $K \vdash \diamond\left(\diamond^{n} \mathrm{t} \phi \vee \diamond^{n-1} \mathrm{t} \phi \vee \cdots \vee \diamond \mathrm{t} \phi \vee \mathrm{t} \phi\right) \rightarrow \nabla \diamond^{n} \phi$, from 2, normality.

II) $K \vdash\left(\diamond^{n+1} t \phi \vee \diamond^{n} t \phi \vee \cdots \vee \diamond t \phi\right) \rightarrow \diamond t \diamond^{n} \phi$, distributing diamonds, Io.

I2) $K \vdash\left(\diamond^{n+1} \mathrm{t} \phi \vee \diamond^{n} \mathrm{t} \phi \vee \cdots \vee \diamond \mathrm{t} \phi\right) \rightarrow\left(\diamond \mathrm{t} \diamond^{\mathrm{n}} \phi \vee \mathrm{t} \diamond^{\mathrm{n}} \phi\right)$, weakening II.

I3) $K \vdash\left(\diamond^{n+1} t \phi \vee \diamond^{n} t \phi \vee \cdots \vee \diamond t \phi\right) \rightarrow t \diamond^{n+1} \phi$, from I2, definition of $t$.

I4) $\mathrm{K} \vdash \mathrm{t} \phi \rightarrow \mathrm{t} \diamond^{\mathrm{n}} \phi$, from 9, classical logic.

I5) $\mathrm{K} \vdash \mathrm{t} \phi \rightarrow\left(\diamond \mathrm{t} \diamond^{\mathrm{n}} \phi \vee \mathrm{t} \nabla^{\mathrm{n}} \phi\right)$, weakening the consequent, from I4.

I6) $K \vdash t \phi \rightarrow t \diamond^{n+1} \phi$, from $I 5$ and the definition of $t$.

I7) $K \vdash\left(\diamond^{n+1} t \phi \vee \diamond^{n} t \phi \vee \cdots \vee \diamond t \phi \vee t \phi\right) \rightarrow t \diamond^{n+1} \phi, I 3$ and 16

I8) $K \vdash\left(\diamond^{n+1} t \phi \vee \diamond^{n} t \phi \vee \cdots \vee \diamond t \phi \vee t \phi\right) \leftrightarrow t \diamond^{n+1} \phi$, I7 and 8

COROLLARY $4.9 \mathrm{~K} \vdash$

$\mathrm{t} \diamond^{\mathrm{n}} \square^{\mathrm{m}} \mathrm{p} \leftrightarrow\left(\nabla^{\mathrm{n}} \mathrm{t} \square^{\mathrm{m}} \mathrm{p} \vee \diamond^{\mathrm{n}-1} \mathrm{t} \square^{\mathrm{m}} \mathrm{p} \vee \cdots \vee \diamond \mathrm{t} \square^{\mathrm{m}} \mathrm{p} \vee \mathrm{t} \square^{\mathrm{m}} \mathrm{p}\right)$

Proof: Instance of Lemma $4.8, \square^{\mathrm{m}} \mathrm{p}$ for $\phi$.

LEMMA 4.IO $\mathrm{K} \vdash$

$\left[\square \mathrm{t} \square^{\mathrm{n}-1} \diamond^{\mathrm{m}} \neg \mathrm{p} \wedge \diamond\left(\diamond^{\mathrm{n}} \mathrm{t} \square^{\mathrm{m}} \mathrm{p} \vee \mathrm{t} \diamond^{\mathrm{n}-1} \square^{\mathrm{m}} \mathrm{p}\right)\right] \rightarrow \diamond \diamond^{\mathrm{n}} \mathrm{t} \square^{\mathrm{m}} \mathrm{p}$

Proof: I) $\mathrm{K} \vdash(\square \phi \wedge \diamond(\psi \vee \neg \phi)) \rightarrow \diamond \psi$, basic theorem of $\mathrm{K}$.

2) $\mathrm{K} \vdash\left[\square \mathrm{t} \square^{\mathrm{n}-1} \diamond^{\mathrm{m}} \neg \mathrm{p} \wedge \diamond\left(\diamond^{\mathrm{n}} \mathrm{t} \square^{\mathrm{m}} \mathrm{p} \vee \neg \mathrm{t} \square^{\mathrm{n}-1} \diamond^{\mathrm{m}} \neg \mathrm{p}\right)\right] \rightarrow \diamond \diamond^{\mathrm{n}} \mathrm{t} \square^{\mathrm{m}} \mathrm{p}$, from I; Let $\phi$ be $t \square^{n-1} \diamond^{m} \neg p$ and $\psi$ be $\diamond^{n} t \square^{m} p$.

3) $\mathrm{K} \vdash \neg \mathrm{t} \square^{\mathrm{n}-1} \diamond^{\mathrm{m}} \neg \mathrm{p} \leftrightarrow \mathrm{t} \diamond^{\mathrm{n}-1} \square^{\mathrm{m}} \mathrm{p}$, from Corollary $\mathrm{r} .7$

4) $\mathrm{K} \vdash\left[\square \mathrm{t} \square^{\mathrm{n}-1} \diamond^{\mathrm{m}} \neg \mathrm{p} \wedge \diamond\left(\diamond^{\mathrm{n}} \mathrm{t} \square^{\mathrm{m}} \mathrm{p} \vee \mathrm{t} \nabla^{\mathrm{n}-1} \square^{\mathrm{m}} \mathrm{p}\right)\right] \rightarrow \diamond \diamond^{\mathrm{n}} \mathrm{t} \square^{\mathrm{m}} \mathrm{p}$, from lines 2 and 3 .

LEMMA 4.II $\mathrm{K} \vdash$

$\left[\square \mathrm{t} \square^{\mathrm{n}-1} \diamond^{\mathrm{m}} \neg \mathrm{p} \wedge \diamond\left(\diamond^{\mathrm{n}} \mathrm{t} \square^{\mathrm{m}} \mathrm{p} \vee \diamond^{\mathrm{n}-1} \mathrm{t} \square^{\mathrm{m}} \mathrm{p} \vee \cdots \vee \diamond \mathrm{t} \square^{\mathrm{m}} \mathrm{p} \vee \mathrm{t} \square^{\mathrm{m}} \mathrm{p}\right)\right] \rightarrow$ $\Delta \diamond^{n} t \square^{m} p$

Proof: Using a version of Corollary 4.9 we have,

I) $K \vdash\left(\diamond^{n-1} t \square^{m} p \vee \ldots \vee \diamond t \square^{m} p \vee t \square^{m} p\right) \leftrightarrow t \diamond^{n-1} \square^{m} p$

2) $K \vdash\left[\square t \square^{n-1} \diamond^{m} \neg p \wedge \diamond\left(\diamond^{n} t \square^{m} p \vee \diamond^{n-1} t \square^{m} p \vee \cdots \vee \diamond t \square^{m} p \vee t \square^{m} p\right)\right] \rightarrow$ $\diamond \diamond^{n} t \square^{m} p$, (use the equivalence on line r and substitute into Lemma 4.IO).

LEMMA 4.I2 $K \vdash\left(\neg t \nabla^{n} \square^{m} p \wedge \diamond t \nabla^{n} \square^{m} p\right) \rightarrow\left(\neg t \diamond^{n} \square^{m} p \wedge \nabla^{n+1} t \square^{m} p\right)$ 
Proof: I) K $\vdash\left(\square t \square^{n-1} \diamond^{m} \neg p \wedge \diamond t \diamond^{n} \square^{m} p\right) \rightarrow \diamond^{n+1} t \square^{m} p$, with Corollary 4.9, substitute $t \diamond^{n} \square^{m} p$ for $\left(\diamond^{n} t \square^{m} p \vee \diamond^{n-1} t \square^{m} p \vee \cdots \vee \diamond t \square^{m} p \vee t \square^{m} p\right)$ in Lemma 4.II

2) $\mathrm{K} \vdash\left(\left(\square \mathrm{t} \square^{n-1} \diamond^{\mathrm{m}} \neg \mathrm{p} \wedge \mathrm{t} \square^{\mathrm{n}-1} \diamond^{\mathrm{m}} \neg \mathrm{p}\right) \wedge \diamond \mathrm{t} \diamond^{\mathrm{n}} \square^{\mathrm{m}} \mathrm{p}\right) \rightarrow \diamond^{\mathrm{n}+1} \mathrm{t} \square^{\mathrm{m}} \mathrm{p}$, from $\mathrm{I}$, strengthening the antecedent.

3) $\mathrm{K} \vdash\left(\mathrm{t} \square^{\mathrm{n}} \diamond^{\mathrm{m}} \neg \mathrm{p} \wedge \mathrm{t}^{\mathrm{n}} \nabla^{\mathrm{m}} \mathrm{p}\right) \rightarrow \diamond^{\mathrm{n}+1} \mathrm{t} \square^{\mathrm{m}} \mathrm{p}, 2$, from the definition of $\mathrm{t}$.

4) $\mathrm{K} \vdash\left(\neg \mathrm{t} \diamond^{\mathrm{n}} \square^{\mathrm{m}} \mathrm{p} \wedge \Delta t \diamond^{\mathrm{n}} \square^{\mathrm{m}} \mathrm{p}\right) \rightarrow \diamond^{\mathrm{n}+1} t \square^{\mathrm{m}} \mathrm{p}$, from 3, using,

$\mathrm{K} \vdash \mathrm{t} \square^{\mathrm{n}} \diamond^{\mathrm{m}} \neg \mathrm{p} \leftrightarrow \neg \mathrm{t} \diamond^{\mathrm{n}} \square^{\mathrm{m}} \mathrm{p}$ (this follows from Corollary I.77)

5) $K \vdash\left(\neg t \diamond^{n} \square^{m} p \wedge \diamond t \diamond^{n} \square^{m} p\right) \rightarrow\left(\neg t \diamond^{n} \square^{m} p \wedge \diamond^{n+1} t \square^{m} p\right)$, from 4 , adding a conjunct to the consequent from the antecedent.

LEMMA 4.I3 $K \vdash\left(\neg t \diamond^{n} \square^{m} p \wedge \Delta t \diamond^{n} \square^{m} p\right) \leftrightarrow\left(\neg t \diamond^{n} \square^{m} p \wedge \diamond^{n+1} t \square^{m} p\right)$

Proof: From Lemma 4.I2 and Lemma 4.7

LEMMA 4.I4 $\mathrm{K} \vdash \bullet \neg \mathrm{t} \diamond^{\mathrm{n}} \square^{\mathrm{m}} \mathrm{p} \rightarrow \diamond^{\mathrm{n}+1} \square^{\mathrm{m}} \mathrm{p}$

Proof: From Lemma 4.I3, Lemma 4.5 and the definition of $\bullet$.

We now show the main results of this section.

THEOREM 4.I5 If $\phi^{\text {hijk }} \notin \mathrm{KT}$, then,

Either $\mathrm{K} \oplus \phi^{\mathrm{hijk}} \vdash \bullet \neg \mathrm{t} \diamond^{\mathrm{n}} \square^{i} p \rightarrow \mathrm{o}^{j} \mathrm{t} \diamond^{\mathrm{k}}(\mathrm{q} \rightarrow \mathrm{p})$, where $\mathrm{h}=\mathrm{n}+1$

Or $\mathrm{K} \oplus \phi^{h i j k} \vdash \bullet \neg \mathrm{t} \diamond^{n} \square^{k} p \rightarrow o^{h} t \diamond^{i}(q \rightarrow p)$, where $j=n+1$

Proof: If $\phi^{\text {hijk }} \notin \mathrm{KT}$, then by Theorem 3.4 we know,

Either $h \neq 0$ or $i<j$.

CASE $\mathrm{I}: \mathrm{h} \neq 0$.

Let $h=n+1$, thus $\phi^{\text {hijk }}$ is $\diamond^{n+1} \square^{i} p \rightarrow \square^{j} \diamond^{k} p$. Thus,

I) $\mathrm{K} \oplus \phi^{\text {hijk }} \vdash \diamond^{\mathrm{n}+1} \square^{\mathrm{i}} \mathrm{p} \rightarrow \square^{\mathrm{j}} \diamond^{\mathrm{k}} \mathrm{p}$

2) $\mathrm{K} \oplus \phi^{\text {hijk }} \vdash \square^{j} \diamond^{k} p \rightarrow o^{j} t \diamond^{k}(q \rightarrow p)$, from Lemma 4.3

3) $\mathrm{K} \oplus \phi^{\text {hijk }} \vdash \diamond^{n+1} \square^{i} p \rightarrow o^{j} \mathrm{t} \diamond^{k}(q \rightarrow p)$, from I and 2 .

4) $\mathrm{K} \oplus \phi^{\text {hijk }} \vdash \bullet \neg \mathrm{t} \diamond^{n} \square^{i} p \rightarrow \diamond^{n+1} \square^{i} p$, from Lemma 4.I4

5) $\mathrm{K} \oplus \phi^{\text {hijk }} \vdash \bullet \neg \mathrm{t} \diamond^{\mathrm{n}} \square^{i} p \rightarrow \circ^{j} \mathrm{t} \diamond^{k}(q \rightarrow p)$, from 3 and 4 .

CASE 2 : $i<j$. $j$ can't be zero. Let $j=n+1$. $\phi^{\text {hijk }}$ is $\diamond^{h} \square^{i} p \rightarrow \square^{n+1} \diamond^{k} p$. Thus,

I) $\mathrm{K} \oplus \phi^{h i j k} \vdash \diamond^{h} \square^{i} p \rightarrow \square^{n+1} \diamond^{k} p$

2) $\mathrm{K} \oplus \phi^{\mathrm{hijk}} \vdash \diamond^{\mathrm{h}} \square^{\mathrm{i}} \neg p \rightarrow \square^{\mathrm{n}+1} \diamond^{\mathrm{k}} \neg p$, instance of $\mathrm{I}$ ( $\neg$ p for $\mathrm{p}$ ).

3) $\mathrm{K} \oplus \phi^{\text {hijk }} \vdash \diamond^{\mathrm{n}+1} \square^{\mathrm{k}} \mathrm{p} \rightarrow \square^{\mathrm{h}} \diamond^{\mathrm{i}} p$, from 2 , contraposition.

At this point, we revert back to line 2 of case I to derive,

4) $\mathrm{K} \oplus \phi^{h i j k} \vdash \bullet \neg \mathrm{t} \diamond^{\mathrm{n}} \square^{k} p \rightarrow o^{h} t \diamond^{i}(q \rightarrow p)$ 
We now officially define our surrogates.

DEFINITION 4.I6 For each $\phi^{\text {hijk }} \notin K T$, call any theorem of $K \oplus \phi^{\text {hijk }}$ of the following form a SURROGATE FOR $\phi^{\text {hijk, }}$

$$
\bullet \neg \mathrm{t} \diamond^{w} \square^{x} p \rightarrow \circ^{y} t \diamond^{z}(q \rightarrow p)
$$

Where either $\mathrm{h}=\mathrm{w}+\mathrm{I}, \mathrm{i}=\mathrm{x}, \mathrm{j}=\mathrm{y}, \mathrm{k}=\mathrm{z}$, or $\mathrm{j}=\mathrm{w}+\mathrm{I}, \mathrm{k}=\mathrm{x}, \mathrm{h}=\mathrm{y}, \mathrm{i}=\mathrm{z}$.

We will (continue to) use $S\left(\phi^{\text {hijk }}\right)$ as an arbitrary surrogate for $\phi^{\text {hijk }}$. THEOREM 4.I7 For each $\phi^{\text {hijk }} \notin \mathrm{KT}$ there is some $S\left(\phi^{\text {hijk }}\right)$,

$$
\mathrm{K} \oplus \phi^{\text {hijk }} \vdash \mathrm{S}\left(\phi^{\text {hijk }}\right)
$$

Proof: By Theorem 4.I5 and Definition 4.I6

THEOREM 4.I8 For each surrogate $S\left(\phi^{\text {hijk }}\right)$,

$$
\mathrm{K} \vdash \mathrm{tS}\left(\phi^{\text {hijk }}\right) \leftrightarrow \mathrm{S}\left(\phi^{\text {hijk }}\right)
$$

Proof: By definition 4.I6, each $S\left(\phi^{\text {hijk }}\right)$ is of the form,

$$
\bullet \neg \mathrm{t} \diamond^{w} \square^{x} p \rightarrow \circ^{y} t \diamond^{z}(q \rightarrow p)
$$

Clearly, each $S\left(\phi^{\text {hijk }}\right)$ is constructed entirely out of $\phi^{\mathrm{EA}}$ and $\phi^{\square}$ formulas. Thus, by Lemmas I.I and I.3.

$$
\mathrm{K} \vdash \mathrm{t}\left(\bullet \neg \mathrm{t} \diamond^{w} \square^{\mathrm{x}} \mathrm{p} \rightarrow \mathrm{o}^{y} \mathrm{t} \diamond^{z}(\mathrm{q} \rightarrow \mathrm{p})\right) \leftrightarrow\left(\bullet \neg \mathrm{t} \diamond^{w} \square^{\mathrm{x}} \mathrm{p} \rightarrow \mathrm{o}^{\mathrm{y}} \mathrm{t} \diamond^{z}(\mathrm{q} \rightarrow \mathrm{p})\right)
$$

THEOREM 4.I9 Where $S\left(\phi^{\text {hijk }}\right)$ is a surrogate for $\phi^{\text {hijk }}$

$$
\mathrm{K} \oplus \phi^{\text {hijk }} \vdash \mathrm{tS}\left(\phi^{\mathrm{hijk}}\right)
$$

Proof: From Theorems 4.I7 and 4.I8

We end this section with an implementation of the method of constructing a surrogate in Theorem 4.I5 Consider axiom 4, $\square p \rightarrow \square \square p$. Here, $h=0$ but $i<j$ (case 2) so we consider the dual version of $4, \diamond \diamond p \rightarrow \diamond p . S(4)$ is thus,

$$
[(\square \neg p \wedge \neg p) \wedge \diamond(\diamond p \vee p)] \rightarrow(\diamond(q \rightarrow p) \vee(q \rightarrow p))
$$

$\mathrm{K} 4 \vdash \mathrm{S}(4)$, and in this case the reason is trivial: the antecedent of $\mathrm{S}(4)$ is contradictory in K4. That is, the antecedent of S(4) can't be true in a transitive model. The reader is encouraged to use this sentence to show that K4 is not a counterexample to the Boxdot Conjecture (note that a simpler sentence was given in [4]; KT does not prove the 4 axiom, but $\mathrm{K} 4$ proves the translation of the 4 axiom). 


\section{FALSIFYING SURROGATES IN A REFLEXIVE MODEL}

The final step is to show that each $S\left(\phi^{\text {hijk }}\right)$ fails in a reflexive model, so that we know KT $\forall S\left(\phi^{\text {hijk }}\right)$. So far we have shown that for each $\phi^{\text {hijk }} \notin K T$, there is some $\psi$ (namely $S\left(\phi^{\text {hijk }}\right)$ ), such that $K \oplus \phi^{\text {hijk }} \vdash \mathrm{t} \psi$ (by Theorem 4.I9). Thus showing that $S\left(\phi^{\text {hijk }}\right)$ fails in a reflexive model is the final step.

We remark on the use of $(q \rightarrow p)$ in the consequent of $S\left(\phi^{\text {hijk }}\right)$. In many cases, $p$ could replace $(q \rightarrow p)$. However, in other cases, it is necessary (cf. $\left.S\left(D_{c}\right)\right)$ ) thus we use it in all cases for the sake of uniformity.

There will be four cases in total, though two of the four will be subsumed under previous cases. We will work on each case individually, then put them together at the end to show the cases are exhaustive.

Before getting to individual cases we prove some preliminary results.

COROLLARY 5.I $K \vdash \mathrm{t} \square^{\mathrm{n}} \phi \leftrightarrow\left(\square^{\mathrm{n}} \mathrm{t} \phi \wedge \square^{\mathrm{n}-1} \mathrm{t} \phi \wedge \cdots \wedge \square \mathrm{t} \phi \wedge \mathrm{t} \phi\right)$

Proof: This is the dual version of Lemma 4.8 .

COROLLARY $5.2 \mathrm{~K} \vdash$

$\mathrm{t} \square^{\mathrm{n}} \diamond^{\mathrm{i}} \neg \mathrm{p} \leftrightarrow\left(\square^{\mathrm{n}} \mathrm{t} \diamond^{\mathrm{i}} \neg \mathrm{p} \wedge \square^{\mathrm{n}-1} \mathrm{t} \diamond^{\mathrm{i}} \neg \mathrm{p} \wedge \cdots \wedge \square \mathrm{t} \diamond^{\mathrm{i}} \neg \mathrm{p} \wedge \mathrm{t} \diamond^{\mathrm{i}} \neg \mathrm{p}\right)$

Proof: This is an instance of Corollary 5.I. $\diamond^{i} \neg p$ for $\phi$

LEMMA 5.3 If $M, w \models \mathrm{t} \phi$ then $M, w \models \mathrm{t} \diamond^{i} \phi$, for all $i \geqslant 0$

Proof: Assume $M, w \models t \phi$. By disjunction introduction,

$$
M, w \models \diamond^{i} t \phi \vee \diamond^{i-1} t \phi \vee \cdots \vee \diamond t \phi \vee t \phi .
$$

Thus by Lemma $4.8, M, w \models t \diamond^{i} \phi$, for all $i$.

\section{I CASE I}

$h \neq 0, j=0, k<h$.

Since $h \neq 0$, let $h=n+1(n \geqslant 0)$. $\phi^{h i j k}$ is,

$$
\diamond \diamond^{n} \square^{i} p \rightarrow \diamond^{k} p
$$

By Theorem 4.15 there is a surrogate for $\phi^{\text {hijk }}$ of the form,

$$
\mathrm{S}\left(\phi^{\text {hijk }}\right): \bullet \neg \mathrm{t} \diamond^{\mathrm{n}} \square^{\mathrm{i} p} \rightarrow \mathrm{t} \diamond^{\mathrm{k}}(\mathrm{q} \rightarrow \mathrm{p})
$$

By the definition of $\bullet$ we have,

$$
\mathrm{K} \vdash \mathrm{S}\left(\phi^{h i j k}\right) \leftrightarrow\left[\left(\neg \mathrm{t} \diamond^{\mathrm{n}} \square^{i} \mathrm{p} \wedge \diamond \mathrm{t} \diamond^{n} \square^{i} p\right) \rightarrow \mathrm{t} \diamond^{k}(\mathrm{q} \rightarrow \mathrm{p})\right]
$$

From this and Lemma 4.13 we have,

$$
K \vdash S\left(\phi^{h i j k}\right) \leftrightarrow\left[\left(\neg t \diamond^{n} \square^{i} p \wedge \diamond^{n+1} t \square^{i} p\right) \rightarrow t \diamond^{k}(q \rightarrow p)\right]
$$

It is this equivalent version of $S\left(\phi^{\text {hijk }}\right)$ we falsify in a reflexive model.

Let $M=\langle\mathbb{N}, R, V\rangle$, where $x R y$ iff $x=y$ or $y$ is the immediate successor of $x$, and $V(p)=\{m \in \mathbb{N} \mid m>n\}$ and $V(q)=\mathbb{N}$. $S\left(\phi^{\text {hijk }}\right)$ fails at 0 . 
LEMMA $5.4 M, \mathrm{O} \models\left(\neg \mathrm{t} \diamond^{\mathrm{n}} \square^{\mathrm{i} p} \wedge \diamond^{\mathrm{n}+1} \mathrm{t} \square^{\mathrm{i}} \mathrm{p}\right) \wedge \neg \mathrm{t} \diamond^{\mathrm{k}}(\mathrm{q} \rightarrow \mathrm{p})$

Proof: By construction of $M, p$ fails at zero and all successors of zero up to and including $n$. Since $t \neg p=\neg p$, By Lemma 5.3, $t \triangleright^{i} \neg p$ is true at worlds zero through $n$, including $n$. Thus we have,

$$
\mathrm{M}, \mathrm{o} \models \square^{\mathrm{n}} \mathrm{t} \diamond^{\mathrm{i}} \neg \mathrm{p} \wedge \square^{\mathrm{n}-1} \mathrm{t} \diamond^{\mathrm{i}} \neg \mathrm{p} \wedge \cdots \wedge \square \mathrm{t} \diamond^{\mathrm{i}} \neg \mathrm{p} \wedge \mathrm{t} \diamond^{i} \neg \mathrm{p}
$$

Thus, by Corollary 5.2, $M, 0 \models t \square^{n} \diamond^{i} \neg p$. That is, $M, 0 \models \neg t \diamond^{n} \square^{i} p$.

Since $p$ is true at world $n+1$ and all higher worlds, $M, n+1 \models t \square^{i} p$ (regardless of the size of $i$ ), thus $M, 0 \models \diamond^{n+1} t \square^{i} p$.

Since $k<h(=n+1)$, and $p$ fails at all worlds strictly less than $h$ (and $q$ is true everywhere), $M, 0 \models t \square^{k}(q \wedge \neg p)$. That is $M, 0 \models \neg t \diamond^{k}(q \rightarrow p)$.

THEOREM 5.5 $\bullet \neg \mathrm{t} \diamond^{n} \square^{i} p \rightarrow t \diamond^{k}(q \rightarrow p)$ is not a theorem of KT

Proof: In Lemma 5.4 $\mathrm{M}$ is reflexive, thus $\mathrm{KT} \forall \forall \mathrm{S}\left(\phi^{\text {hijk }}\right)$

\subsection{CASE 2}

$h \neq 0, j \neq 0$.

Since $h \neq 0$, let $h=n+1$. $\phi^{\text {hijk }}$ is,

$$
\diamond \diamond^{n} \square^{i} p \rightarrow \square^{j} \diamond^{k} p
$$

By Theorem 4.15, there is a surrogate for $\phi^{\text {hijk }}$,

$$
\mathrm{S}\left(\phi^{h i j k}\right): \bullet \neg \mathrm{t} \diamond^{n} \square^{i} p \rightarrow o^{j} t \diamond^{k}(q \rightarrow p)
$$

Using Lemma 4.I3 as in Case I (Subsection 5.I], we have,

$$
\mathrm{K} \vdash \mathrm{S}\left(\phi^{h i j k}\right) \leftrightarrow\left[\left(\neg \mathrm{t} \nabla^{n} \square^{i} p \wedge \nabla^{n+1} t \square^{i} p\right) \rightarrow o^{j} \mathrm{t} \nabla^{k}(q \rightarrow p)\right]
$$

It is this equivalent version of $S\left(\phi^{\text {hijk }}\right)$ we falsify in a reflexive model.

In the previous section, where $j=0$, the size of $k$ was important. As long as $j \neq 0$, the size of $k$ becomes irrelevant. We now construct our model.

Let $W=\left\{w_{k}, w_{j_{1}}, w_{j_{2}}, \ldots, w_{j_{j-1}}, w_{j_{j}}, 1,2,3, \ldots\right\}$. Note that there are as many $w_{j}$ worlds as there are occurrences of $\circ$ in our surrogate, and by assumption $j \neq 0$, thus there is at least one $w_{j}$ world. On the other hand, we only need one $w_{k}$ world (whether $k=0$ or not). Also, 0 is not in our set of worlds, $w_{j_{j}}$ will take the place of 0 , and our surrogate will fail at $w_{j_{j}}$.

Define a the relation $R$ on $W$ as follows:

$$
\begin{gathered}
w_{j_{j}} R 1,1 R 2,2 R 3, \ldots \text { and, } \\
w_{j_{j}} R w_{j_{j-1}}, w_{j_{j-1}} R w_{j_{j-2}} \ldots w_{j_{2}} R w_{j_{1}}, w_{j_{1}} R w_{k}
\end{gathered}
$$

Using arrows to represent the relation $\mathrm{R}$ we have,

$$
w_{k} \leftarrow w_{j_{1}} \leftarrow \cdots \leftarrow w_{j_{-1}} \leftarrow w_{j_{j}} \rightarrow 1 \rightarrow 2 \rightarrow 3 \rightarrow \cdots
$$


$w_{k}$ relates to no world, and is the only world which relates to no world. $w_{j_{j}}$ relates to exactly two worlds, and is the only world which relates to more than one world. As mentioned in the introduction and shown in Lemmas 2.2 and 2.3. we don't need to add that our model is reflexive. We will officially make it reflexive in our last step.

$$
V(p)=\{m \in\{1,2,3, \ldots\} \mid m>n\} \text { and } V(q)=\left\{w_{k}\right\} .
$$

LEMMA 5.6 $\mathrm{M}, w_{\mathrm{k}} \models \neg \mathrm{t} \diamond^{\mathrm{k}}(\mathrm{q} \rightarrow \mathrm{p})$ for all $\mathrm{k} \geqslant 0$.

Proof: Using Cor. I. $7, \neg t \triangleright^{k}(q \rightarrow p)$ is equivalent to $t \square^{k}(q \wedge \neg p)$. By construction of the model $t \square^{0}(q \wedge \neg p)$ (i.e. $(q \wedge \neg p)$ ) is true at $w_{k}$ (in fact, it is the only world where $\mathrm{q} \rightarrow \mathrm{p}$ fails). By Corollary 5.I and the fact that $w_{k}$ relates to no world, $M, w_{k} \models t \square^{k}(q \wedge \neg p)$ for all k, i.e. $M, w_{k} \models \neg t \diamond^{k}(q \rightarrow p)$.

LEMMA $5.7 M, w_{j_{j}} \models \neg t \diamond^{n} \square^{i} p \wedge \nabla^{n+1} t \square^{i} p$

Proof: As in the previous case, $p$ is true at $n+1$ and all the successors of $n+1$, thus $M, w_{j_{j}} \models \diamond^{n+1} t \square^{i} p$, regardless of the size of $i$.

$p$ fails at all worlds strictly less than $n+1$, all the $w_{j}$ worlds, and $w_{k}$. By Lemma 5.3 (since $t \neg p=\neg p$ ), $\mathrm{t} \diamond^{i} \neg p$ is true at all worlds strictly less than $n+1$, all the $w_{j}$ worlds, and $w_{k}$. Just as in Lemma 5.4 , we use Corollary 5.2 to conclude $M, w_{j_{j}} \models t \square^{n} \diamond^{i} \neg$ p, i.e. $M, w_{j_{j}} \models \neg t \diamond^{n} \square^{i} p$

We now work to show the consequent of our $S\left(\phi^{\text {hijk }}\right)$ fails. First we need, LEMMA 5.8 For all $w \in\{1,2,3, \ldots\}$,

$$
M, w \models o^{v} \mathrm{t} \diamond^{k}(q \rightarrow p) \text { for all } k, v \geqslant 0 .
$$

Proof: By induction on $v$. Base case, $v=0$. By construction of the model for all $w \in\{1,2,3, \ldots\}, M, w \models(q \rightarrow p)$ (since $q$ fails at all these worlds). Since $\mathrm{t}(\mathrm{q} \rightarrow \mathrm{p})=(\mathrm{q} \rightarrow \mathrm{p})$, we use Lemma 5.3 to conclude $M, w \models t \triangleright^{\mathrm{k}}(\mathrm{q} \rightarrow \mathrm{p})$, for all $w \in\{1,2,3, \ldots\}$, all $k \geqslant 0$.

For the inductive step assume $M, w \models o^{v} t \diamond^{k}(q \rightarrow p)$ for all $w \in\{1,2,3, \ldots\}$. By construction of the model, each number relates to (and only to) its immediate successor. Thus, by the induction hypothesis, at each $w, M, w \models$ $\square \circ^{v} t \triangleright^{k}(q \rightarrow p)$. Thus,

$$
M, w \models o^{v} t \diamond^{k}(q \rightarrow p) \rightarrow \square \circ^{v} t \diamond^{k}(q \rightarrow p)
$$

That is, by the definition of $\circ, M, w \models \circ^{v+1} t \diamond^{k}(q \rightarrow p)$

The final step is to show $\circ^{j} t \nabla^{k}(q \rightarrow p)$ fails at $w_{j_{j}}$.

LEMMA 5.9 For each $w_{j_{m}}$,

$$
\mathrm{M}, w_{j_{\mathrm{m}}} \models \neg \mathrm{o}^{\mathrm{m}} \mathrm{t} \diamond^{\mathrm{k}}(\mathrm{q} \rightarrow \mathrm{p}) \text {, and for all } \mathrm{z}<\mathrm{m}, \mathrm{M}, w_{j_{\mathrm{m}}} \models \mathrm{o}^{z} \mathrm{t} \diamond^{\mathrm{k}}(\mathrm{q} \rightarrow \mathrm{p})
$$


Proof: By induction on $m$. Since, by assumption, $j$ is not zero, and there are as many $w_{j}$ worlds as there are occurrences of $\circ$, our base case is $m=1$. Thus to show the base case we need to show,

$$
\mathrm{M}, w_{j_{1}} \models \neg \circ \mathrm{t} \diamond^{\mathrm{k}}(\mathrm{q} \rightarrow \mathrm{p}) \text {, and } \mathrm{M}, w_{j_{1}} \models \circ^{o} \mathrm{t} \diamond^{\mathrm{k}}(\mathrm{q} \rightarrow \mathrm{p})
$$

Thus we must show $M, w_{j_{1}} \models \bullet t \diamond^{k}(q \rightarrow p)$, and $M, w_{j_{1}} \models t \diamond^{k}(q \rightarrow p)$.

By construction $M, w_{j_{1}} \models \neg q$, thus $M, w_{j_{1}} \models q \rightarrow p$. Since $t(q \rightarrow p)=$ $(q \rightarrow p)$, use Lemma 5.3 to conclude $M, w_{j_{1}} \models t \diamond^{k}(q \rightarrow p)$.

By Lemma 5.6, $M, w_{k} \models \neg t \diamond^{k}(q \rightarrow p)$. Since $w_{j_{1}} R w_{k}$, we have,

$$
M, w_{j_{1}} \models \diamond \neg t \diamond^{k}(q \rightarrow p)
$$

Since $M, w_{j_{1}} \models t \diamond^{k}(q \rightarrow p)$, by the definition of $\bullet, M, w_{j_{1}} \models \bullet t \diamond^{k}(q \rightarrow p)$

For the inductive step assume,

$$
\begin{gathered}
M, w_{j_{m}} \models \neg o^{m} \mathrm{t} \diamond^{k}(q \rightarrow p), \\
\text { and for all } z<m, M, w_{j_{m}} \models o^{z} t \diamond^{k}(q \rightarrow p)
\end{gathered}
$$

We must show,

$$
\begin{gathered}
M, w_{j_{m+1}} \models \neg o^{m+1} \mathrm{t} \diamond^{k}(q \rightarrow p), \\
\text { and for all } z<m+1, M, w_{j_{m+1}} \models o^{z} t \diamond^{k}(q \rightarrow p)
\end{gathered}
$$

For a reductio, assume, for some $z<m+1, M, w_{j_{m+1}} \models \neg o^{z} \mathrm{t} \nabla^{k}(q \rightarrow p)$.

Thus, $M, w_{j_{m+1}} \models \bullet o^{z-1} \mathrm{t} \diamond^{k}(q \rightarrow p)$, and hence, $M, w_{j_{m+1}} \vDash \diamond \neg o^{z-1}$ $\mathrm{t} \diamond^{\mathrm{k}}(\mathrm{q} \rightarrow \mathrm{p})$. Now, it is possible that $w_{j_{\mathrm{m}+1}}$ is $w_{j_{j}}$, but even if it is, by Lemma 5.8. $\neg \mathrm{o}^{z-1} \mathrm{t} \diamond^{\mathrm{k}}(\mathrm{q} \rightarrow \mathrm{p})$ can't be true at the number 1. Thus, whether or not $w_{j_{m+1}}$ is $w_{j_{j}}$, it must be the case that $M, w_{j_{m}} \models \neg o^{z-1} \mathrm{t} \diamond^{k}(q \rightarrow p)$. But this contradicts the induction hypothesis (Since $z<m+1, z-1<m$ ).

Thus we know,

$$
\text { For all } z<\mathrm{m}+1, M, w_{j_{\mathrm{m}+1}} \models \circ^{z} \mathrm{t} \diamond^{k}(q \rightarrow p)
$$

And in particular we know: $M, w_{j_{m+1}} \models \circ^{m_{t}} \diamond^{k}(q \rightarrow p)$.

By the induction hypothesis $M, w_{j_{m}} \models \neg 0^{m} t \diamond^{k}(q \rightarrow p)$, since $w_{j_{m}+1} R w_{j_{m}}$, we have,

$$
\begin{gathered}
M, w_{j_{m+1}} \models \diamond \neg o^{m} \mathrm{t} \diamond^{k}(q \rightarrow p) \\
\text { So, } M, w_{j_{m+1}} \models \bullet o^{m} \mathrm{t} \diamond^{k}(q \rightarrow p), \text { i.e. } M, w_{j_{m+1}} \models \neg o^{m+1} t \diamond^{k}(q \rightarrow p) . \\
\text { COROLLARY 5.IO } M, w_{j_{j}} \models \neg o^{j} t \diamond^{k}(q \rightarrow p)
\end{gathered}
$$

Proof: From Lemma 5.9, let $\mathrm{m}=\mathrm{j}$.

LEMMA 5.II $M, w_{j_{j}} \models \neg t \diamond^{n} \square^{i} p \wedge \diamond^{n+1} t \square^{i} p \wedge \neg o^{j} t \diamond^{k}(q \rightarrow p)$

Proof: From Corollary 5.10 and Lemma 5.7

THEOREM 5.I2 KT $\forall \bullet \neg \mathrm{t} \diamond^{\mathrm{n}} \square^{\mathrm{i} p} \rightarrow \mathrm{o}^{\mathrm{j}} \mathrm{t} \diamond^{\mathrm{k}}(\mathrm{q} \rightarrow \mathrm{p})$ 
Proof: By Lemma 5.II, a sentence equivalent to $S\left(\phi^{\text {hijk }}\right)$ fails in a model.

As mentioned it is sufficient to show $S\left(\phi^{\text {hijk }}\right)$ fails in some model. For if $S\left(\phi^{\text {hijk }}\right)$ fails, so does $t S\left(\phi^{\text {hijk }}\right)$ (by Theorem 4.I8). $t S\left(\phi^{\text {hijk }}\right)$ is a boxdot formula, thus by Lemma 2.3, we can reflexivize the model and $\mathrm{tS}\left(\phi^{\text {hijk }}\right)$ will still be false (and so $S\left(\phi^{\text {hijk }}\right)$ will also fail).

We now present our final results.

THEOREM 5.I3 Where $S\left(\phi^{\text {hijk }}\right)$ is a surrogate for $\phi^{\text {hijk }}, \mathrm{KT} \forall \mathrm{S}\left(\phi^{\mathrm{hijk}}\right)$.

Proof: Let $S\left(\phi^{\text {hijk }}\right)$ be a surrogate for $\phi^{\text {hijk }}$. By definition, $\phi^{\text {hijk }} \notin \mathrm{KT}$, thus by Theorem 3.4 we know that for $S\left(\phi^{\text {hijk }}\right)$,

I) Either $h \neq 0$ or $i<j$, and

2) Either $j \neq 0$ or $k<h$.

Assume $h \neq 0$. Now either $j \neq 0$ or $j=0$. If $j=0$, then $k<h$, and $S\left(\phi^{\text {hijk }}\right)$ is not a theorem of KT, by Theorem 5.5 in Subsection 5.I. (Case I). If $j \neq 0$, then $S\left(\phi^{\text {hijk }}\right)$ is not a theorem of KT, by Theorem 5.12 (Case 2).

Assume $i<j$. In this case $j$ can't be zero. Now either $h \neq 0$ or $b=0$. If $h=0$ then by Theorem 4.15. $S\left(\phi^{h i j k}\right)$ is $\bullet-t \nabla^{n} \square^{k} p \rightarrow t \diamond^{i}(q \rightarrow p)$, where $j=n+1$. In this case our argument is the same as Case 1. Assume $h \neq 0$. This is subsumed by Case 2 .

THEOREM 5.I4 For all $\phi^{\text {hijk }} \notin K T,(\exists \psi)\left(K \oplus \phi^{\text {hijk }} \vdash \mathrm{t} \psi\right.$ and $\left.K T \forall \psi\right)$

Proof: By Theorem 4.I9. for all $\phi^{\text {hijk }} \notin \mathrm{KT}$ there is some $S\left(\phi^{\text {hijk }}\right)$, and $\mathrm{K} \oplus$ $\phi^{\text {hijk }} \vdash \mathrm{tS}\left(\phi^{\text {hijk }}\right)$. By Theorem 5.13, KT $\forall S\left(\phi^{\text {hijk }}\right)$

COROLlary 5.15 The Boxdot Conjecture holds for all $\mathrm{K} \oplus \phi^{\text {hijk }}$.

Proof: It holds trivially when $\phi^{\text {hijk }} \in \mathrm{KT}$. If $\phi^{\text {hijk }} \notin \mathrm{KT}$ use Theorem 5.I4

\section{ACKNOWLEDGMENTS}

I thank an anonymous referee for many comments which greatly improved this article. I also thank Brian Schmitz (for being a mensch).

\section{REFERENCES}

[I] G. Boolos, The Logic of Provability, 1993, Cambridge U. Press, Cambrdige, Mass.

[2] A. P. Brogan, "Aristotle's logic of statements about contingency," Mind, 76 (1967), pp. 46-8I.

[3] M. J. Cresswell. "Necessity and contingency," Studia Logica, 47:2 (1988), pp. $145-149$, 
[4] R. French, L. Humberstone, "Partial confirmation of a conjecture on the boxdot translation in modal logic," The Australasian fournal of Logic, volume 7 (2009), pp. 56-6r.

[5] R. Goldblatt, "Solution to a completeness problem of Lemmon and Scott," Notre Dame Fournal of Formal Logic, I6:3 (1975), pp. 405-408.

[6] E. Goris, "Interpreting knowledge into belief in the presence of negative introspection," Technical Report TR-2007005, CUNY Ph.D. Program in Computer Science, 2007.

[7] L. Humberstone, "The logic of non-contingency," Notre Dame fournal of Formal Logic, 36:2 (1995), pp. 214-229.

[8] S. Kuhn, "Minimal non-Contingency logic," Notre Dame fournal of Formal Logic, 36:2 (1995), pp. 230-234.

[9] A Lomuscio, W. van der Hoek "A logic for ignorance," Electronic Notes in Theoretical Computer Science, 85:2 (2004).

[ro] J. Marcos, "Logics of essence and accident," Bulletin of The Section of Logic, 34:I (2005), pp. 43-56.

[II] H. Montgomery, R. Routley, "Non-contingency axioms for $\mathrm{S}_{4}$ and $\mathrm{S}_{5}$," Logique et Analyse, I2 (1969), pp. 422-428.

[12] C. Mortensen, "A sequence of normal modal systems with non-contingency bases," Logique et Analyse, I9 (1976), pp. 34I-344.

[13] C. Steinsvold "A note on logics of ignorance and borders," Notre Dame Fournal of Formal Logic, 49:4 (2008), pp. 385-292.

[14] C. Steinsvold "Completeness for various logics of essence and accident," The Bulletin of the Section of Logic, 37: 2 (2008), pp. 93-IO2.

[15] E. Zolin, "Completeness and definability in the logic of non-contingency," Notre Dame fournal of Formal Logic, 40:4 (1999), pp. $533-547$. 
The Australasian fournal of Logic (ISSN I448-5052) disseminates articles that significantly advance the study of logic, in its mathematical, philosophical or computational guises. The scope of the journal includes all areas of logic, both pure and applied to topics in philosophy, mathematics, computation, linguistics and the other sciences.

Articles appearing in the journal have been carefully and critically refereed under the responsibility of members of the Editorial Board. Only papers judged to be both significant and excellent are accepted for publication.

The journal is freely available at the journal website at

$$
\text { http://www.philosophy.unimelb.edu.au/ajl/ }
$$

All issues of the journal are archived electronically at the journal website.

SuBSCRIPTIONS Individuals may subscribe to the journal by sending an email, including a full name, an institutional affiliation and an email address to the managing editor at ajl-editors@unimelb.edu.au Subscribers will receive email abstracts of accepted papers to an address of their choice. For institutional subscription, please email the managing editor at ajl-editors@unimelb.edu.au.

Complete published papers may be downloaded at the journal's website at http: //www.philosophy.unimelb.edu.au/ajl/ The journal currently publishes in pdf format.

Submission The journal accepts submissions of papers electronically. To submit an article for publication, send the $\mathrm{LT}_{\mathrm{E}} \mathrm{X}$ source of a submission to a member of the editorial board. For a current list of the editorial board, consult the website.

The copyright of each article remains with the author or authors of that article. 